\title{
Skin Contact with Gold and Gold Alloys
}

\section{EFFECTS AND POSSIBLE CAUSES OF BLACK DERMOGRAPHISM AND METAL SMUDGE}

\author{
William S. Rapson \\ Consultant, International Gold Corporation, Johannesburg, South Africa
}

\begin{abstract}
The ordinary person comes into contact with metallic gold and gold alloys either through the wearing of gold jewellery or as a consequence of the use of these materials in dental restorations and prostheses. In what follows, knowledge of the effects of such contact, gleaned from literature studies, will be reviewed.
\end{abstract}

\section{Reactions of the Skin}

Three types of reaction merit discussion. First, there is the effect known as black dermographism, in which stroking with certain metals immediately produces well defined black lines on the skin. Some gold alloys are amongst such metals. The evidence indicates that the effect is the result of impregnation of the skin with black metallic particles generated by mechanical abrasion of the metal by contaminants of the skin. There is no positive and unequivocal evidence of the ability of metals to mark uncontaminated skin so rapidly that it is possible to write upon it.

Secondly there are the two related phenomena of the wear of gold jewellery, and the susceptibility of certain individuals to blackening of the skin where it is in contact with such jewellery. The occurrence of smudge, as it is often called, is not very common, but is brought to the attention of most jewellers from time to time. In extreme cases it may make it embarrassing for the person concerned to wear metallic jewellery. It would appear as if gold smudge results also mainly from mechanical abrasion of jewellery, though this may be aided and/or supplemented in some instances by corrosion of gold or gold alloy induced by certain components of the sweat.

Finally, there is the question of true allergic responses to contact of the skin with gold and its alloys. Judging from the very few cases which have been recorded, such responses are extremely rare.

Some recent observations on the reactions of gold $(0)$ with amino acids and of reaction to contact of the skin with gold on the part of theumatoid arthritis patients undergoing gold therapy, are, however, relevant in this connection.

This review will deal predominantly with the first two of these effects.

\section{Black Dermographism of Gold and Gold Alloys}

Although there is a reference by Bechet, in discussion of a 1943 paper of Urbach and Pillsbury (1), to a monograph in French on dermographism, published some sixty years previously, no details are given of this work and it has not proved possible to identify it. It was stated, however, that the monograph contained a chapter on black dermographism which included reference to the part played by this phenomenon in demonology, black magic and witchcraft in the Middle Ages.

It is apparent, therefore, that the fact that it is possible to write on the skins of certain individuals with certain metals has long been known.

The earliest scientific description of the effect in the English language which has been identified, is contained in a note from King's College Hospital in London in 1879 by Ferrier (2) who followed up an observation by a colleague, Wood, on a patient with paralysis of the cervical sympathetic on the left side and complete paraplegia from the midthoracic region downwards. Wood had noted that a silver probe made dark pencil marks on the paralysed parts, whereas it produced only red marks of vascular dilatation on the unparalysed parts of the patient. Ferrier found, inter alia, that the edge of a bright sovereign, which would almost certainly have been of the standard 22 carat alloy, produced dark marks similar to those made by silver, though less readily and less distinctly. $\mathrm{He}$ observed black marking also with copper, lead, zinc and magnesium but only red vascular dilatation markings with iron, platinum and arsenic.

During the course of his experiment, he burnished one of the metals he was using with wash-leather, and noting that this was blackened in the process, he tested all the metals on wash-leather and found them to behave towards it as they did towards the skin of the paralysed parts of his patient. He finally concluded that the blackening was the result of metal abrasion, which produced black particles of metal, that it was an attribute to a greater or lesser extent of all healthy skin, but that under certain conditions, especially of oedema, the effect was intensified.

The next identified publication was from Russia, where Emdin in 1925, also came across black dermographism by chance and followed it up in collaboration with his colleague Kusmenko at the State University at Rostow-on-Don. Together, these investigators studied some 800 patients in neighbouring clinics, hospitals and sanatoria. They concluded (3) that if skin was dry, oiled by very thorough rubbing in of vaseline and powder applied, it was possible to make black marks upon it with a number of metals. In the light of this and the immediate nature of the blackening reaction, they dismissed the possibility of a chemical mechanism for black dermographism and concluded, as had Ferrier previously, that the effect was purely a mechanical one, with powder contamination of the skin playing a crucial tole.

This paper stimulated studies of further aspects of the phenomenon by investigators in Russia and Germany. A few of these and in particular, Breitmann (4), Jurjew (5) and Russinow and Sutorochin (6) postulated chemical mechanisms, but these enjoyed little support. The majority including Hauck and Dietel (7), Kranz (8), Hosp (9), Bork (10), Dietel(11), Joch (12), Riehl(13), Goldschlag 
(14) and Koga (15)concluded from their studies that the mechanism was indeed mechanical and associated with contamination of the skin with mineral particles.

Aspects of the work of these and subsequent investigators which are relevant in the context of the present review are described in more detail below.

\section{Metals Which Produce Black Dermographism}

A list (1) of metals producing black dermographism includes not only gold 'less fine than 18 carat' but also silver, copper, aluminium, nickel, zinc, tin, lead and brass. This list could be expanded. A parallel list of metals which do not produce the effect includes gold 'finer than 18 carat', along with iron and platinum.

Unfortunately in regard to the gold alloys tested no details of compositions or metallurgical histories are given. The data are therefore, incomplete and possibly unreliable. This aspect is discussed in detail later in this review.

\section{Contaminants of the Skin Which Promote Black Dermographism}

Following on the original work of Emdin and Kusmenko, information accumulated rapidly concerning the role of contaminants in promoting the marking of skin by metals. Thus Breitmann (4) found that black dermographism occurred not only with women who used face or body powders, but also with factory and other workers who worked in dusty environments and who never used such powders. Thus Markow, Beilin and Minkina (17) reported a high incidence of black dermographism amongst persons engaged in such occupations as cement mixing, stucco work, etc. A number of workers ((7) and (9) especially) found contamination with zinc oxide particularly effective.

The most exhaustive study of contaminants, however, was that of Urbach and Pillsbury (1) who studied the effects of a wide range of powdered materials under standardized conditions, and included in their investigations a study of twenty brands of face powder. All brands made writing on skin possible and of their constituents titanium dioxide and calcium carbonate were particularly effective in this respect. The authors were unable to find any correlation, however, between occurrence of the effect and the relative hardnesses of the metal and powder combinations used in the tests.

\section{Effects of Skin Properties}

Non-fatty and dry skins were found to mark much more easily than fatty and/or moist skins. This was interpreted as due to the lubricating effects of fat and moisture. It explained, for example, why the skin between the breasts or in the middle of the back was marked more easily than that on the forehead (7). The latter was found to have a higher fat content (9). The horny layer of the skin was also found to play a role. Thus it has been found that it is easier to write on the thick keratin of the palm of the hand than it is to write on the inner side of the upper arm.
Effects of Disease, Endocrine Disturbances etc.

A number of workers have studied the incidence of black dermographism on patients and others suffering from various disturbances of health.

An early suggestion (3) that susceptibility to writing on the skin with metals was especially common amongst patients suffering from hysteria was later found untenable and abandoned (16). The most comprehensive studies were probably those of Hosp (9) and Hauck and Dietel (7), who studied such susceptibility in a wide range of subjects suffering from various venereal and skin diseases, from disturbances of endocrine function, from malfunctioning of organs and from a range of miscellaneous conditions. No correlations could be drawn and a particular susceptibility to skin writing amongst patients suffering from skin diseases was found attributable to external treatments of these diseases with medicaments containing zinc oxide.

In regard to the effects of endocrine disturbances, ability to write on the skin was at first thought to be enhanced in patients suffering from thyroid deficiency, but this was never substantiated.

Perhaps of greatest interest, especially in relation to the marking of the skin by jewellery, however, was a claim by Rühl (17a) that the skin of women during the premenstrual period was particularly prone to blackening by jewellery, especially where there was actual rubbing, as opposed to gentle contact, between it and the skin. Rühl's claims were later followed up by a number of investigators including Spier (18), Genzel (19), Albrecht (20), Polemann(21) and Hauck and Dietel (7). In the light of the available information Rühl's claims were not regarded as convincing by Soltermann (22). Polemann and Spier had attributed blackening of the skin to the formation of sulphides of the metals, generated by their interaction with labile sulphide compounds in the sweat which was seen as being hormonally controlled during the premenstrual period. Both Spier and Genzel had recommended treatment with vitamin Cand diuretics in such cases and claimed that this cured the tendency to blackening of the skin by jewellery.

\section{Confirmation of the Abrasive Mechanism}

Microscopic examination of marked skin has been described by many workers, who have recorded the presence on it of specks of black material. In the case of paper impregnated with zinc oxide particles and marked with a gold ring, the particles had a golden gleam.

Of more significance, however, is an electron mictoscopy study described by Soltermann (22), which yielded confirmation of the presence, in black markings, of relatively large particles of abraded metal.

Wear of Gold Jewellery by Friction with the Skin, and the Smudge Phenomenon

Wear of gold jewellery may be caused in a number of ways; through rubbing against the skin and clothes, through friction 
between component parts such as the links in chains, and through tarnish and corrosion. In the light of the review of black dermographism above, it will be apparent that the abrasive mechanism established for it must also be operative in respect of wear caused by rubbing against the skin.

There is, however, a very important difference between the conditions under which skin may be marked when it is written upon using gold and gold alloys and the conditions under which jewellery made of the same alloys comes into contact with the skin when it is worn. In writing upon skin there is transient frictional contact between the metal and the skin, whereas in the wearing of gold jewellery, contact between the skin and the jewellery may be prolonged and may vary considerably in nature from gentle contact as in the case of a pendant to close rubbing contact as in the case of a ring, bangle, watch or watch-band.

Moreover, gold jewellery may be worn intermittently and seldom cleaned before use, in which case it may have on it before it is worn, thin films of dried perspiration and adherent dust and - in the case of low caratage items - of the products of tarnishing which may have taken place while it was being stored. There is the possibility in the case of such jewellery that the skin may be marked not necessarily by the metal but by transfer to it of contaminants of the metal. There is also the possibility that where jewellery is tarnished or corroded, this may involve preferential attack on one or more of the jewellery alloy components by surface enrichment and may leave the surface of the alloy more susceptible to abrasion.

Established facts in this whole area of gold jewellery wear and of smudge production are very few and the task of generating them is very difficult. Appropriate attention must be paid not only to the metallurgical histories of the alloys (23) but also to the degree and nature of the contamination of the skin with abrasive powders and to the factors which may promote tarnishing and corrosion.

The following discussion highlights those aspects of the subject which are of significance.

\section{Abrasive Wear'Through Friction with the Skin and Dermographism}

Our knowledge of black dermogtaphism indicates that wear should be increased and smudge production made more likely where jewellery is worn by persons with dry, non-oily skins and where use is made of face or body powders. Very little powder may be needed, the effects of one application may endure for an appreciable time, and may extend beyond the site of original application. Even if powder is not used, contamination of the skin by abrasive particles may occur as a result of exposure to dusty environments or fabrics. The between-breasts and mid-back positions may cause more wear and show more frequent smudge production than might be expected from the gentle nature of the contacts between jewellery and skin in these positions, because of the relatively non-oily character of their skin. Both wear of, and marking, by carat gold rings, bangles, watch-cases and watch-bands may be greatly enhanced as a result of handling of or contact with dust or grit generally.

Rubbing of jewellery items by fabrics impregnated by abrasive particles may be a factor in the wear of the alloys involved and may lead to marking of the fabrics.

\section{Effects of Caratage and Metallurgical Histories on Wear of Gold Jewellery}

Because of it softness, low strength and great ductility pure gold is not suitable for jewellery unless this is of massive construction. It

\begin{tabular}{|c|c|c|c|c|}
\hline \multicolumn{2}{|c|}{$\begin{array}{l}\text { Alloy Composition, } \\
\text { wt. } \%\end{array}$} & \multirow[t]{2}{*}{ Specimen pretreatment } & \multirow{2}{*}{$\begin{array}{c}\text { Vickers } \\
\text { hardness, } \\
\text { HV }\end{array}$} & \multirow[t]{2}{*}{$\begin{array}{l}W^{-1}, \\
\mathrm{~m} / \mu \mathrm{m}\end{array}$} \\
\hline Standard & Additives & & & \\
\hline \multirow{10}{*}{$\begin{array}{l}\text { Au } 58.5 \\
\text { Ag } 26.0 \\
\text { Cu } 15.5\end{array}$} & & $\begin{array}{l}\text { quenched from } 750^{\circ} \mathrm{C} \\
\text { quenched from } 750^{\circ} \mathrm{C} \text { and annealed at }\end{array}$ & 120 & 2.43 \\
\hline & & $350^{\circ} \mathrm{C}$ for $1 \mathrm{~h}$ & 237 & 2.07 \\
\hline & & $\begin{array}{l}\text { cold worked (deformation grade: } 70 \% \text { ) } \\
\text { cold worked }(70 \%) \text { and annealed at }\end{array}$ & 272 & 1.94 \\
\hline & & $280^{\circ} \mathrm{C}$ for $5 \mathrm{~h}$ & 312 & 2.17 \\
\hline & $0.7 \mathrm{Co}$ & quenched from $750^{\circ} \mathrm{C}$ & 168 & 2.19 \\
\hline & $0.7 \mathrm{Co}$ & $\begin{array}{l}\text { quenched from } 750^{\circ} \mathrm{C} \text { and annealed } \\
\text { isothermally at } 280^{\circ} \mathrm{C} / 3 \mathrm{~h}\end{array}$ & 341 & \\
\hline & $0.25 Y$ & quenched from $750^{\circ} \mathrm{C}$ & 155 & 2.68 \\
\hline & $0.25 \mathrm{Y}$ & cold worked $(70 \%)$ & 271 & 2.54 \\
\hline & $0.39 \mathrm{Zr}$ & quenched from $750^{\circ} \mathrm{C}$ & 175 & 2.51 \\
\hline & $0.39 \mathrm{Zr}$ & cold worked $(70 \%)$ & 271 & 2.44 \\
\hline
\end{tabular}

Table I

Abrasive Wear Resistance, $w^{-1}$, of a 14 Carat Gold Alloy in Different Metallurgical States Measured after $250 \mathrm{~m}$ Sliding Distance. After (24) 
scratches easily and might therefore be expected to wear rapidly by abrasion. It is nevertheless not listed among metals which mark skin, even when this has been contaminated by a material such as zinc oxide powder. This appears anomalous, but may be explained in terms of the findings of Heidsiek and Clasing. These authors recently described in this journal (24) the results of an investigation of the abrasive wear of one 18 carat and two 14 carat gold jewellery alloys by 'microcut', which is a polishing cotton normally used in the preparation of metallurgical microsections and which is lightly impregnated with silicon carbide particles ( $\leqq 15 \mu \mathrm{m}$ ).

The hardnesses of the alloys were varied by a range of mechanical and thermal pre-treatments and, in the case of one of the 14 carat alloys, by the incorporation of additives (grain refiners). The abrasive wear resistances of the alloys in their different forms were then measured under standardized conditions. Details of the results are reproduced in Tables I and II.

Although the hardness of the one 14 carat alloy could be varied between $120 \mathrm{HV}$ (soft state) and $312 \mathrm{HV}$ (cold worked and annealed state), increase in hardness was not accompanied by increase in wear resistance (Table I). Indeed under the test conditions, the abrasive wear resistance in the hardest state was 10 per cent less than that in the soft state. These results indicate that, contrary to what is often presumed, hardness is not a suitable indicator of abrasive wear resistance for this alloy. In fact the highest wear resistance was observed in the case of the alloy in a soft state ( $155 \mathrm{HV}$ ) which was achieved by addition to it of 0.25 per cent of yttrium.

This conclusion was confirmed in the more limited studies of the other 14 carat alloy and of the 18 carat alloy (Table II).

These findings are readily understood in terms of the two mechanisms for abrasive wear which are generally recognized, namely micro-cutting and micro-ploughing. The amount of material removed, and therefore the wear rate, is high if microcutting prevails, since it leads to immediate material loss. In microploughing, however, the surface undergoes mainly deformation without material loss. The higher the ability of a surface to absorb plastic deformation, the higher will be the extent to which mictoploughing occurs and the higher the wear resistance.

It is tempting to extrapolate from these results and from the tribological conditions employed by Heidsiek and Clasing and to conclude from their findings that the failure of pure gold to mark skin is a consequence of its ease of deformation and therefore a predominance of micro-ploughing over micro-cutting during rubbing by the skin. It is also tempting to conclude that the abrasive wear of gold jewellery by skin and therefore its dermographic effectiveness must be less affected by its caratage, than by its ability to undergo plastic deformation in the state in which it is tested. It would be rash, however, to be in any way dogmatic about conclusions drawn on this basis even though Taylor (25) has demonstrated in practical trialsconducted over a period of one year that 18 carat gold alloys can be equally as durable as those of 9 carat purity.

\section{The Role of Tarnish and Corrosion in the Wear of GoldJewellery in} Contact with Skin

The literature on the tarnishing of gold alloys used in electrical contacts by exposure to the atmosphere in a wide range of environments is extensive. For the purpose of the present teview perhaps the most important facts which have emerged are first, the tendency for overall resistance to tarnish to increase with gold content of the alloy and, secondly, the important role which sulphur compounds can play in the tarnishing especially of lower gold content alloys. Experience has confirmed that these findings also apply to the carat gold alloys used in jewellery fabrication. Only low caratage alloys tarnish, and then only in more aggressive environments. The work of Treacy and German on the tarnish and corrosion characteristics of dental gold alloys reported in the last issue of this journal ((Gold Bulll., 1984, 17, (2), 46-54) is of interest in this respect and confirms these trends.

The type of tarnishing which is of greatest significance for the wear of gold jewellery and the marking by it of the skin, is that which may be promoted by substances secreted by or derived from the skin. The substances of most immediate interest in this connection are amino acids and in particular the sulphur-containing amino acids. Recent investigations reviewed by the author in Gold Bulletin (26) have suggested that metallic gold in the soil can be rendered soluble and taken up by plants and micro-organisms through reaction with amino acids, and in the case of certain plants, through reaction with cyanide generated from cyanogenetic glycosides, which are secreted into the soil.

In this connection the work of Brown, Smith, Fox and Sturtock (27) who have recently studied the reactions of gold in the form of foil and as colloidal gold with a range of amino acids, both sulphurcontaining and sulphut-free, is very significant. The uptake of gold from the massive form in different solutions is shown overleaf in Table III.

\begin{tabular}{|c|c|c|c|}
\hline \multicolumn{4}{|c|}{$\begin{array}{l}\text { Table II } \\
\text { Abrasive Wear Resistance, } w^{-1} \text {, of } 18 \text { and } 14 \text { Carat Gold } \\
\text { Alloys in Various Metallurgical States. After (24) }\end{array}$} \\
\hline $\begin{array}{l}\text { Alloy } \\
\text { composition, } \\
\text { wt. } \%\end{array}$ & $\begin{array}{l}\text { Specimen } \\
\text { pretreatment }\end{array}$ & $\begin{array}{l}\text { Vickers } \\
\text { hardness, } \\
\text { HV }\end{array}$ & $\begin{array}{l}w^{-1} \\
\mathrm{~m} / \mu \mathrm{m}\end{array}$ \\
\hline $\begin{array}{l}\text { Au } 75 \\
\text { Cu } 25\end{array}$ & $\begin{array}{l}\text { quenched from } 750^{\circ} \mathrm{C} \\
\text { cold worked }(70 \%) \text { and } \\
\text { annealed at } 300^{\circ} \mathrm{C} \\
\text { for } 1 \mathrm{~h}\end{array}$ & 155 & 2.25 \\
\hline $\begin{array}{l}\text { Au } 58.5 \\
\text { Cu } 36.0 \\
\text { Ni } 5.5\end{array}$ & $\begin{array}{l}\text { quenched from } 750^{\circ} \mathrm{C} \\
\text { cold worked }(70 \%)\end{array}$ & $\begin{array}{l}126 \\
280\end{array}$ & 3.49 \\
\hline
\end{tabular}




\begin{tabular}{|c|c|c|c|c|}
\hline Amino acid & $\mathrm{pH}$ & $\begin{array}{c}\text { Gold uptake, } \\
\mu \mathrm{g} / \mathrm{ml}\end{array}$ & $\begin{array}{l}\text { Solution } \\
\text { appearance }\end{array}$ & $\begin{array}{l}\text { The Effect of } \mathrm{pH} \text { on the Solubility of } \\
24 \text { carat Gold in } 10^{-1} \mathrm{M} \text { Solution of }\end{array}$ \\
\hline L-cysteine & $\begin{array}{l}1.2 \\
7.2 \\
9.5\end{array}$ & $\begin{array}{r}0.3 \\
2.0 \\
22.1\end{array}$ & $\begin{array}{l}\text { black precipitate } \\
\text { white/black precipitate } \\
\text { white precipitate }\end{array}$ & $\begin{array}{c}\text { Alanine and Histidine Solutions } \\
\text { which were Analysed after Standing } \\
\text { in Contact with the Gold for One } \\
\text { Month. After (27) }\end{array}$ \\
\hline glutathione & $\begin{array}{l}1.6 \\
7.2 \\
9.5\end{array}$ & $\begin{array}{r}0.6 \\
8.0 \\
33.1\end{array}$ & $\begin{array}{l}\text { black precipitate } \\
\text { black precipitate } \\
\text { black precipitate }\end{array}$ & \\
\hline D-penicillamine & $\begin{array}{l}1.6 \\
7.2 \\
9.5\end{array}$ & $\begin{array}{r}0.4 \\
10.2 \\
18.5\end{array}$ & $\begin{array}{l}\text { black precipitate } \\
\text { black precipitate } \\
\text { black precipitate }\end{array}$ & $=$ \\
\hline L-alanine & $\begin{array}{l}1.6 \\
7.2 \\
9.5\end{array}$ & $\begin{array}{l}0.2 \\
0.1 \\
0.2\end{array}$ & $\begin{array}{l}\text { clear solution } \\
\text { clear solution } \\
\text { clear solution }\end{array}$ & \\
\hline L-histidine & $\begin{array}{l}1.6 \\
7.2 \\
9.5\end{array}$ & $\begin{array}{l}1.2 \\
2.1 \\
1.8\end{array}$ & $\begin{array}{l}\text { faint black precipitate } \\
\text { faint black precipitate } \\
\text { faint black precipitate }\end{array}$ & \\
\hline
\end{tabular}

Like Russian investigators before them, whose work is described in (26), they found that over a long period (1 month), significant amounts of gold were dissolved by solutions of sulphur-containing amino acids such as L-cysteine, glutathione and D-penicillamine while much smaller amounts were dissolved by sulphur-free amino acids such as L-alanine and L-histidine. Solution took place with the formation of black or white precipitates in some instances and was favoured by raising the $\mathrm{pH}$ in the case of the thiol-containing amino acids. The precipitates contained gold and appeared to be gold complexes when white, and largely metallic gold - presumably formed as a result of the decomposition of initially formed but unstable complexes - when they were black. The addition of hydrogen peroxide facilitated the attack on the gold by the sulphurfree amino acids. Hydrogen peroxide could not be used with the thiol-containing amino acids because of its reaction with them to form disulphides.

As a most interesting extension of their work on gold itself, Brown et al. studied the dissolution of gold and copper from a series of massive gold-copper alloys by L-histidine and glycine in the presence of hydrogen peroxide. The results (Table IV) suggest that the peroxide accelerated the oxidative dissolution of metal and that the higher the copper content of the alloy the more gold and copper were dissolved. This is in tune with the known ease of solution of copper in amino acids. The enhanced solubility of the gold was interpreted as possibly due to the increased area exposed by the dissolving copper. These limited experiments are sufficient to demonstrate that a range of amino acid solutions is capable of dissolving at least gold and copper from carat gold alloys and therefore from jewellery made from such alloys. Moreover dissolution was often found to occur with the production of dark precipitates.

The circumstantial evidence therefore strongly suggests that the oxidative dissolution of gold and other metals from carat gold alloys, in the presence of amino acids secreted or derived from the skin, plays a role not only in the wear of carat gold jewellery items, especially rings, watch cases, bangles and watch-bands, but also in the production of smudge by such items. Other substances secreted by the skin, and in particular sodium chloride, may also be factors in the tarnishing and cortosion of carat gold alloys. Contamination of the skin with sodium chloride, from the handling of common salt or from sea water or sea spray may reinforce the effects of sodium chloride in sweat.

\section{Other Aspects of Gold Smudge Formation}

Although metallic abrasion and corrosion are generally recognised (28) as potential causes of smudge formation in the majority of subjects who appear to be susceptible to it, the possibility that medical and biochemical factors may be involved in some instances cannot be excluded.

Thus one case has been placed on record (29) of a diabetic patient whose hands were stained black whenever she handled gold and silver. On treatment with insulin this no longer occurred. However the black staining reappeared immediately following ingestion of excess of glucose. As yet this observation has not been followed up. 


\begin{tabular}{|c|c|c|c|c|c|c|}
\hline \multirow{3}{*}{$\begin{array}{c}\text { Table IV } \\
\text { Gold and Copper Concentrations } \\
\text { ( } \mu \mathrm{g} / \mathrm{ml}) \text { from } 9,18,22 \mathrm{ct} \text {. Gold in } \\
\text { Histidine and Glycine }\left(10^{-1} \mathrm{M}\right) \\
\text { Solutions With and Without Hydrogen } \\
\text { Peroxide }\left(10^{-1} \mathrm{M}\right) \text {. After }(27)\end{array}$} & $\begin{array}{l}\text { Amino acid } \\
\text { histidine }\end{array}$ & \multirow{2}{*}{$\begin{array}{c}\begin{array}{c}\text { Gold alloy, } \\
\text { ct. }\end{array} \\
9 \\
18 \\
22\end{array}$} & \multicolumn{2}{|c|}{$\begin{array}{l}\text { Solution conce } \\
\text { gold copper } \\
\text { (no hydrogen } \\
\text { peroxide) }\end{array}$} & $\begin{array}{l}\text { ion, } \mu \mathrm{g} / \\
\text { gold } \\
\text { (wit } \\
\text { p }\end{array}$ & $\begin{array}{l}\text { copper } \\
\text { gen } \\
\text { e) }\end{array}$ \\
\hline & histidine & & $\begin{array}{l}4.7 \\
1.9 \\
1.2\end{array}$ & $\begin{array}{l}1.2 \\
1.2 \\
0.6\end{array}$ & $\begin{array}{r}11.1 \\
7.1 \\
6.8\end{array}$ & $\begin{array}{r}21.8 \\
1.3 \\
0.6\end{array}$ \\
\hline & glycine & $\begin{array}{r}9 \\
18 \\
22\end{array}$ & $\begin{array}{l}0.6 \\
0.3 \\
0.2\end{array}$ & $\begin{array}{l}0.3 \\
0.3 \\
0.3\end{array}$ & $\begin{array}{l}4.6 \\
3.6 \\
3.2\end{array}$ & $\begin{array}{l}1.0 \\
0.5 \\
0.4\end{array}$ \\
\hline
\end{tabular}

\section{Allergic Responses to Skin Contact with Gold and Gold Alloys}

Although parenterally administered gold salts are a known cause of dermatitis, and there have been reports of dermatitis caused by skin contact with gold(III) chloride and with potassium gold (I) cyanide solutions (31-38), cases of contact sensitivity to metallic gold or gold alloys have rarely been described. Metallic gold, carat gold jewellery alloys and dental gold alloys are widely accepted as nonsensitizing or non-allergenic materials which are safe and inert in contact with the skin or oral mucosa even over long periods of time. Such acceptance is based upon the fact that although countless millions of people weat or have worn gold jewellery or have, or have had, dental restorations or prostheses made of gold alloys, clinical cases of allergic contact dermatitis to gold are so seldom encountered as to be virtually unknown. Thus in 1971 (39) Elgart and Higdon were able to describe only seven cases of gold allergy which had previously been reported in the literature (40-46) and of these one had not been confirmed by patch testing. The number of such cases which have been described has not grown significantly since then $(47-65)$.

Some aspects of these rare allergic responses to gold which merit attention are the following:

(1) It is unlikely that they could be produced by gold or gold alloys in the metallic state. They therefore indicate that certainly with the rare people who are sensitive to contact with gold, and possibly also with all people to a greater or less extent, gold in both the pure and alloyed form is converted in small amounts, probably by the action of amino acids in the sweat, into soluble form and absorbed into/or through the skin.

(2)That this is the case has been confirmed by Brown et al. (27) who found gold in amounts of 0.09 and $0.07 \mathrm{mg} / \mathrm{g}$, in two samples of skin taken from below gold rings on fingers.

(3) The ability of gold to move in the reverse direction from blood to skin is well established and skin disorders are a well documented (66) complication of the gold therapy of theumatoid arthritis. Moreover Brown et al. (27) have referred to a publication (in press) by Sturrock concerning a history of patients who, on starting chrysotherapy, produce rashes specifically in those areas of their skin which have been in contact with gold jewellery. The rashes are apparently different, both in speed of appearance and specificity of site from the skin rashes which are 'normally' associated with gold injections. Brown et al. speculate as to whether those specific rashes may not be examples of skin irritancy resulting from injected gold reaching parts of the skin already sensitized by absorbing gold.

(4)In the case of those few persons who suffer skin irritation or dermatitis as a result of wearing carat gold jewellery, the possibility must be borne in mind - even if sensitivity to gold can be demonstrated by patch tests - that this sensitivity may be enhanced by other metals being absorbed by the skin along with the gold.

(5)In contrast to massive carat gold jewellery, items in the production of which gold has been plated over other metals have frequently been identified as the cause of skin irritation. The cause in virtually all cases that have been studied (67) has been either the use of an undercoat of nickel beneath the gold, or the use of a nickel-containing gold alloy as the substrate. Nickel is strongly allergenic.

(6)In general, therefore, gold must be seen as a metal which at least possesses the potential capablility of producing skin reactions. That it does so in very rare cases, is almost certainly to be attributed partly to its nobility, which hinders the production from it in significant amounts of soluble gold salts capable of being absorbed by the skin, and partly to the very small proportion of persons in whom absorbed gold reaches pathogenic concentrations.

(7)In view of the above it is indeed remarkable that adverse reactions to gold are virtually unknown in dentistry. This may be in some measure a reflection of the extent to which gold restorations and prostheses are 'irrigated' in the mouth. It may also be a consequence of the almost exclusive use, up to a few years ago, of high gold-content alloys selected in part for their high resistance to tarnish and corrosion. 


\section{References}

1 E. Urbach and D.M. Pillsbury, J. Am. Med. Assoc., 1943, 121, 485-490 2 D. Ferrier, Brit. Med. J., 1879, 1, 341

3 P.J. Emdin and A. Kusmenko, Medicinskaja mysl., 1925, 3, 72-74

4 M. Breitmann, München. Med. Wchnschr, 1929, 76, 634; Med. Biol. Ztschr,(Russ.), 1928, 4, 29-35

5 F.S. Jurjew, Klin. Med. (Russ.), 1928, 6, (8/83), 489-490

6 A.J. Russinow and W.H. Sutorichin, Irkutsk, Med.J., 1929, 7, 345

7 Hauck and F. Dietel, Arch. F. Syph. (Kongressber), 1930, 126; Klin. Wcbnschr, 1929, No 39; Zentralbl. f. Haut u. Geschlechtskr, 1929, 31, 413

8 W. Krantz, Münch. Ned. Wchnschr, 1929, 76, 1295

9 E. Hosp, Dermatol. Wchnschr., 1930, 91, (52), 1895-1904

10 A. Bork, Ztschr, Ges. Neurol. Physchiat., 1930, 123, 224

11 F. Dietel, Dermatol. Wchnschr, 1931, 92, 950-952

12 W. Joch., Dissertation, Erlangen, 1931

13 G. Riehl, Zentralbl. f. Haut u. Geschlechtskr, 1931, 37, 325

14 F. Goldschlag, Zentralbl. f. Haut, u. Geschlechtskr., 1930, 32, 795

15 K. Koga, Hifu-to-Hitsunyo, 1933, 1, 451

16 P.J. Emdin, Münch. Med. Wchnscbr, 1930, 76, 2055-2056

17 Markow, Beilin and Minkina, Klin. Med. (Russ.), 1930, No.

17a K. Rühl, Dermatol. Wchnschr., 1912, 54, 581

18 HW. Spier, Münch Med. Wcbnschr, 1952, 2044

19 H. Genzel, Münch. Med. Wchnschr, 1940, 1, 1244

$20 \mathrm{H}$. Albrecht, Münch. Med. Wchnschr, 1940, 1, 74

21 G. Polemann, Deutsch. Med. Wchnschr. 1954, 1100

22 W. Soltermann, Dermatologica, 1954, 110, 16-22

23 W.S. Rapson and T. Groenewald, 'Gold Usage', Academic Press, London, 1978, pp. $38-39$

24 H. Heidsiek and M. Clasing, Gold Bull., 1983, 16, (3), 76-81

25 B. Taylor, Aurum, 1981, (6), 46-50

26 W.S. Rapson, Gold Bull., 1982, 15, (1), 19-20

27 D.H. Brown, W.E. Smith, P. Fox and R.D. Sturrock, Inorg. Chim. Acta., 1982, $67,27-30$

28 G.E. Gardam, Special Report No. 4 to the Worshipful Company of Goldsmiths, London, 1969, (See also Keystones (a circular to jewellers), 1967)

29 G. Sell, Balance (J. Brit. Diabet. Assoc.), 1937, December, 11

30 L. Schwartz, L. 'Tulpan and D.J. Birmingham, 'Occupational Diseases of the Skin', 3rd Edition, Henry Kimpton, London, 1957

31 E. Cronin, 'Contact Dermatitis', Churchill Livingstone, London, New York, 1980

32 M.G. Budden and D.S. Wilkinson, Contact Dermatitis, 1978, 4, (3), 172-173
33 B.A. Sonov and G.D. Chajmosku, Vest. Derm. Vener, 1964, 38, 33-36 34 E. Schmollack, Dermatol. Ztschr, 1971, 157, 821-

35. C. Nava and C. Briatico-Vangosa, Medicina de Lavoro, 1971, 62, 572-578

36 E. Sidi and M. Hincky, J. Investig. Dermatol., 1966, 47, 369 .

37 K.E. Malten and J.W.H. Mali, Allergie Asthma, 1966, 12, 31-36

38 W.B. Shelley and E. Epstein, Arch. Dermatol., 1963, 87, 388-391

39 M. Elgart and R.S. Higdon, Arch. Dermatol, 1971, 103, 649-653

40 L.E. Gaul, Ann. Allergy, 1954, 12, 429-449

41 S. Comaish, Arch. Dermatol., 1969, 99, 720-722

42 J.M. Fox, R. Kennedy and A. Rostenberg, Arch. Dermatol, 1961, 83, 956-959

43 A. Rostenberg and A.J. Perkins, J. Allergy, 1951, 22, 466-474

44 H.W. Forster and R.F. Dickey, Am. J. Opthalmol., 1949, 32, 659-662

45 E. Chenoweth, Med.J. Austral., 1957, 2, 20

46 M. Elgart, Arch. Dermatol., 1972, 106, 254

47 M.A. Cowan, Brit. J. Dermatol., 1960, 72, 348-349

48 A. Bowyer, Acta Dermatol-Venereol., 1967, 47, 9-14

49 H. Petios and A.L. Macmillan, Brit. J. Dermatol, 1973, 88, 505-508

50 M. Rytter and H. Schubert, Dermatologica, 1971, 142, 209-218

51 E. Young, Dermatologica, 1974, 149, 294-298

52 E. Schöpf, O. Wex and K.H. Schultz, Hautartz, 1970, 21, 422-424

53 M.A. Cooke and D.E. Hocken Robertson, Contact Dermatitis Newsletter, 1973 13, 382-

54 F. Klaschka, Contact Dermatitis, 1975, 1, 264-265

55 S. Fregert, M. Hollander and J. Paulsen, Contact Dermatitis, 1979, 5, 63-64

56 A.A. Fisher, Cutis, 1974, 14, 177-179

57 R. Holland-Moritz, M. Rimpler and P.O. Rudolph, Dtsch. Zahnaerztl. Z, 1980 $35,(10), 963-967$

58 M. Spreng, in 'Die Zahn-, Mund-und Kiefer Keilkunde, 4 Band', Urban an Schwarzenberg, München, 1956, pp. 44-63

59 H.R. Roenigh and D. Handel, Arch. Dermatol, 1974, 109, 253-255

60 C.G. Roeleveld and W.E. van Ketel, Contact Dermatitis, 1975, 1, 333-334

61 R. Söremark, K. Wing, K. Olsson and J. Goldin, J. Prostbet. Dent., 1968, 20, (6), 531-540

62 E. Bauer, Dtsch. Zabnaerstl. Z, 1963, 18, 1023

63 S.O. Törnell, Sver. Tandlaeakarfoerb. Tidn., 1962, 54, 151-

64 N.M. Burvikov et al., Stomatologiia (Mosk.), 1973, 52, 80

65 D. Hertmann, Münch. Med. Wchnschr., 1977, 119, (8), 265-270

66 A. Bogg, Acta Dermatol-Venereol., 1957, 37, 338-352

67 L.E. Gaul, J. Am. Med. Assoc., 1967, 200, (2), 176-178 